\title{
A Pragmatic View of Wisdom with Rational Ethics
}

\author{
Zbigniew J. Gackowski \\ California State University Stanislaus, Turlock, CA, USA
}

\author{
ZGackowski@csustan.edu
}

\begin{abstract}
This is a theoretical paper; it presents the author's position about how to pragmatically view wisdom through the lens of decision making as a factor in human-controlled operations for computerized knowledge management. It refers to the Data-Information-Knowledge-Wisdom (DIKW) Hierarchy, considered by some as the canon of information science and knowledge management, where wisdom is listed but rarely discussed. Wisdom is viewed by various authors as a state of mind or consciousness or a degree of knowledge with subsequent corresponding actions; it may aim only at a passive adjustment to existence or at its transformation. Within a defined system of references, many doubts can be dispelled, limits of rational thinking recognized, and the need for resorting to trial and error realized to detect and counter the unintended consequences of one's actions. Some of the views foster, others hinder, advances in science, technology, and economy. This paper posits that a pragmatic approach to wisdom, when combined with rational ethics, may facilitate a practical understanding of wisdom and computerized management of it and may fill the existing gap in scholarly literature with the DIKW model, which has been revised to the IDCKW model, where "Concepts" play the central role.
\end{abstract}

Keywords: Wisdom, pragmatism, praxiology, knowledge, bounded rationality, indirect cognition, rational ethics, Information-Data-Concept-Knowledge-Wisdom model

Thesis: Viewing wisdom as a state of mind appears to be unproductive, while viewing wisdom as a target idea of complete knowledge with subsequent actions, as imperfect as they may be at present, contributes to advances of science, technology, and economy and makes wisdom amenable to computerized knowledge management.

\section{Introduction and Motivation}

\section{The Gap in the DIKW Sequence}

Frank Blackler (1995), in his seminal study, outlined an alternative approach to knowledge. He views it as a complex process that is mediated, situated, provisional, pragmatic, and contested;

Material published as part of this publication, either on-line or in print, is copyrighted by the Informing Science Institute. Permission to make digital or paper copy of part or all of these works for personal or classroom use is granted without fee provided that the copies are not made or distributed for profit or commercial advantage AND that copies 1) bear this notice in full and 2) give the full citation on the first page. It is permissible to abstract these works so long as credit is given. To copy in all other cases or to republish or to post on a server or to redistribute to lists requires specific permission and payment of a fee. Contact Publisher@InformingScience.org to request redistribution permission. however, he does not discuss wisdom. Martin Fricke (2009) reviewed the DataInformation-Knowledge-Wisdom (DIKW) Hierarchy as "part of the canon of information science and management," identified a central logical error in it, and suggested an alternative. About the same time, Jean-Baptiste P. L. Faucher, Andre M. Everett, and Rob Lawson (2008), independently from Fricke, embarked upon reconstituting 
knowledge management. They proposed a new model from Existence to Enlightenment (E2E) as a "cognitive system of knowledge" that redefines the scope of knowledge management. They criticize the current approaches for lack of clear boundaries of knowledge and have added Existence at the lower end and Enlightenment at the upper end of the model.

The final nail to the esteemed DIKW model was offered by Targowski in 1990 and again in 2011. He says that, without the Concept (level), the DIKW model ultimately always takes the form of a mental or formal model for action; otherwise, there is no need for wisdom. He added Concept to it and thus defined the DICKW model. Without a concept or model of action, the DIKW model, which he criticizes, is of little or no practical value for pragmatic considerations. Even more, "concept" automatically assumes the central position, which usually is attributed to wisdom. One can test whether data or information are factual without a concept of action, but only in action will the outcomes show that any of them actually impact the results of actions and whether they are of significant materiality, which, in practice, counts above anything else. Without a model of action, one cannot even determine whether information or data is relevant at all and whether it is wise to apply it or not.

Except for Targowski, most authors left wisdom in the DIKW or DICKW model but did not discuss it. Rowley (2007) did an extensive analysis of the recently published texts on the DIKW Hierarchy with particular emphasis on 16 textbooks that are most likely read by a large number of students. She concluded: "Despite being at the top of the DIKW hierarchy, wisdom is a neglected concept in the knowledge management and information system literature (Rowley, p. 178). Wisdom was only defined by three books, and other higher levels were mentioned by two authors" (Rowley, p. 170).

Gackowski (2012c) proposed a more elaborate approach to knowledge management along an ascending and expanding helix of human cognition that incorporates quality assurance at each step of advancement and monitors the managed knowledge for currency by way of feedback from practice. This departs from the current way of thinking, but he never went beyond a call for a pragmatic approach to wisdom. Recent publications about this topic include Cognitive informatics and wisdom development: Interdisciplinary approaches, by Andrew Targowski (2011), and Some Reflections on Wisdom, by Bogdan Stefanowicz (2012).

Targowski dedicated an entire book to wisdom; it is a gold mine of references to all types of statements made about this subject since the dawn of civilization. He employs concepts from Cognitive Informatics to wisdom in likely the broadest known approach; it also aims at the wisdom of entire civilizations. He posits, to the surprise of many, that wisdom can be taught; and actually teaches it to honors students. He discusses how ideologies, science, technology, and spirituality contribute to wisdom, and he presides over the International Society for the Comparative Study of Civilizations. His view of wisdom seems to emphasize rational decision making within the confines of not clearly defined ethics. Targowski $(2011,2012)$ defines wisdom this way:

Human wisdom is a combination of individual, family, profession, and civilization wisdoms applying, according to the needs: BASIC, WHOLE, GLOBAL, and UNIVERSAL MINDS in order to provide practical, moral, theoretical, and method-oriented worldliness and universality, proceeding to prudent judgments and choices of concepts. They are supported by data, information, and knowledge - leading to conclusions, positions, solutions, decisions, actions, and so forth, which are understandable, competent, and sensitive.

Thus, human wisdom incorporates that of family, profession, and civilization. Of course, one may add more environmental components, which can impact an individual's wisdom. For example, neighborhood wisdom (or "smartness") is perceived in this study of civilization wisdom as the most aggregate unit of cultural experiences. A short, practical definition of wisdom, according to Targowski (2012), is as follows: 
Wisdom is based upon skilful judgment and choice driven by the art of life. For many, the art of life still can be a puzzle. The key to this puzzle is in understanding and learning how to cope with the components and factors of wisdom.

Reflections, by Stefanowicz (2012), were written independently and likely without knowledge of Targowski's book on the US market. Stefanowicz, in his own words, limited himself to "posing many questions" (p. 3), and he accepted all quoted statements without objection as containing "some cognitive load," with the purpose of identifying some common platform. He arrived at the conclusion that the notion of wisdom is of such a broad meaning that it remains indefinable; he claims that the same also applies to information and knowledge. This sounds like an intellectual unconditional surrender.

No wonder! Even Britannica does not offer a separate entry about wisdom, despite the fact that it is the oldest term, while data is the newest term in English (Faucher et al., 2008, p. 4). A broader view of wisdom (than the Western) in religions and philosophies should not ignore JeeLoo Liu (2006), who, in the best introduction to Chinese philosophy (heavily influenced by Indian philosophy), reveals some stunning differences of seemingly lasting consequence. The Western and the Chinese cultures are of comparably long traditions. Chinese philosophy stresses the interconnection of Mind and Reality, of no polar oppositions; it emphasizes adjustment to and divination of the rhythm of the Universe- a prerequisite for wisdom in ancient folk religion (Liu, pp. 3-4), which is continued in Daoism (Liu, pp. 22-23), and is deprived of any "otherworldly" consideration. Thus, on the one hand, it is a "this-worldly" realistic philosophy, while on the other hand, it takes a passive attitude toward reality in contrast to many Western philosophies and religions that recommend more active, even aggressively transformative attitudes toward existence.

The above motivates us to present wisdom in a way that fits the needs of computerized knowledge management. Thus, we define wisdom, viewed pragmatically, as complete knowledge of verifiable granules (more about this below) that is assessed by the praxiological triad of criteria: ethics (here the rational one), effectiveness in meeting the purpose, and efficiency that measures ratio of benefits with regard to purpose against the input used. This is the main thread of this paper; however, it is used within the Information-Data-Concepts-Knowledge-Wisdom (DICKW) model of thinking.

\section{Pragmatism to the Rescue}

Readers rightly expect some progress in the era of digital computers and nanotechnology. Our reality is as discrete as digital computers. Just as atomic theory and, later, quantum mechanics revealed the granular nature of matter, we note that data stored in computers, and possibly even knowledge in the mind, can be described as granular. The terms we apply to wisdom should be adequate to the state of science and technology. We cannot blame the quoted authors (selected from a time interval of several millennia) for using fuzzy terms (undefined numerals, ordering relations without criteria, etc.). Today, we expect better, while in reflection, anything goes.

A scientific answer needs a defined system of references, the lack of which leads to confusion in scholarly discussions in any domain. Philosophy of science offers guidelines. Statements made within a defined system of references, even when some prefer a different one, can be translated from one system into another. One may reliably navigate, whether using the Ptolemaic or Copernican model of planetary movements within our solar system; only the latter is simpler and closer to reality. In discussions, scholars infrequently distinguish necessities, characteristics (distinguishing properties), sufficient reasons, and only "nice" add-ons, but these distinctions are essential.

General terms employed in discussions such as "justified," "positive," "good," "truth," "proper," "appropriate," "difficult," "correct," "the best," "the highest," "according to its nature," "values," 
“convictions," "artful," "skillful," even "liberty," etc. are pragmatically without meaning if they cannot be applied, verified, or questioned. Wisdom, if within a defined system of references, can be more easily viewed, interpreted, understood, and managed. This paper uses terms with referents that are demonstrable, observable, and verifiable (in contrast to "accepted," which is preferred by some reviewers but worthless in science); it will discuss wisdom from the bottom up, not from lofty heights. Because even dictionaries fail with regard to facts, it is assumed that facts pertain to things that exist that are verifiable by any observer and events that verifiably occurred. In operations, contingencies must also be considered, such as the potential of finding explosives in a search because, in action, they must be taken into account.

This paper presents the author's position in a positivist down-to-earth manner that views information, informing, data, and knowledge as representations that can be tested within the context of a concept or model for actions as physical phenomena and interpreted pragmatically by the difference in results of action when a factor is used or not; it makes no reference to ontology, about the nature of being, and to epistemology that studies the nature of knowledge. It

1. presents a pragmatic model of wisdom within a defined system of references.

2. emphasizes the use of natural semantics (of material pragmatic consequences of decisions followed by action of measurable results with regard to ethics, purpose (effectiveness; the main point of reference in teleological viewed human-controlled operations), and their efficiency.

3. recognizes a gradual granular quantitative extension of understanding of our existence, which is meant as reality that is presented in experience until a critical point is reached that triggers qualitative changes.

4. postulates the universal teleological perspective and relativity of assessing increments of understanding with regard to purposes that are defined within the praxiological triad of criteria: ethics (here the rational one), effectiveness (purpose), and efficiency.

5. limits its scope only to demonstrable, verifiable, and replicable (in tests) increments of knowledge; they may be divorced from the "accepted" ones for millennia, as was once the view that the sun revolves around the planet earth.

Section 2 lays out the pragmatically viewed model of accumulating wisdom. Section 3 confronts the model with selected statements about wisdom made by scholars. Section 4 discusses the role of rational ethics that is necessary for pragmatic wisdom, while Section $\mathbf{5}$ presents conclusions with the further revised IDCKW model, the limitations of the pragmatic approach to wisdom with rational ethics, and the need for further exploration of other approaches to knowledge management.

This paper is presented for challenge, critique, and discussion. For focused reading, key terms are in bold print and emphasis in italics or CAPS. Terms accompanied or followed by a definition appear in bold italics. An outline of what is meant by pragmatic accumulating wisdom follows.

\section{A Pragmatic View of Accumulating Wisdom}

In its essence, pragmatism is a doctrine that holds that the meaning of an idea or a proposition lies in its observable practical consequences (pragmatism, AHTD, 1997). Scholarly literature emphasizes interpretations made within linguistic semantics, while this paper uses natural semantics, which attributes operational meaning of entities by the difference in results of reasoning and action when applied versus not applied; it excludes the operational interpretations made in computer science. We are in a better position than the authors from a long time ago. "I could see 
farther because I was standing on the shoulders of giants, "wrote Newton in 1676 in his letter to Hooke (Google).

By historical experience and by Schopenhauer (1974), will is a sufficient reason for action; however, it may not be a wise action. The decision about action may be controlled by reason and analytical intellect. To BE wise, pragmatically does not carry any meaning; hence, wisdom should manifest its existence in results of reasoning and subsequent action. To live, humans MUST act. In inorganic matter, the direction of processes (natural) is determined from a higher to a lower potential, from a lower to a higher state of entropy. In organic matter, there are no movements without some purpose, including communication. Einstein (1951) advises us to make observations of phenomena by defining the main point of reference, the frame of reference (context), and a yardstick - unit of measure. Hence, in human actions, the natural main point of reference is a measurable purpose that is articulated and assessed within the praxiological triad of criteria.

\section{Praxiology and Wisdom}

Processes in organic nature, including human actions, are subject to the postulate of teleological perspectivism and context of assessments. Assessments of factors, here wisdom, within a concept or model of subsequent operations are defined and assessed within the praxiological triad of criteria: ethics, effectiveness (the extent to which purpose is attained), and efficiency (the ratio of benefits with regard to purpose to the inputs used):

1. The applicable ethics, here the rational ethics, as discussed in Section 4; for instance, Kant's categorical imperative of guidance for individuals, Milton Friedman's "Provided they stay within the law, corporate executives should make as much money for shareholders as possible," or Margolis et al. (2005), "Up to code: Does your company's conduct meet world-class standards?" for for-profit public corporations, or the utilitarian approach claims that, "If the benefits outweigh the costs, then it is ethical" for nonprofits. With the latter, however, we face the danger that the end may justify anything.

2. The teleological perspectivism, with perspectivism as defined by Nietzsche (2007) - the selected view or outlook.

3. The context within which factors (here wisdom) are applied in a real situation, similar to the restricted relativity defined by Einstein (1961, p. 13) - the results of an observation depends on its context (that includes the concept or model of action or operations), or frame of reference.

The frame of reference includes all stakeholders in the results and all the environmental circumstances of action, including the concept of conducting it. Entities are assessed equally unless the purpose (measured by effectiveness) and frame of reference change. If a change occurs, it changes how even the physically identical entities are assessed differently by decision makers. One of the reviewers asked what is wise to do in one's spare time when there is no need for action imposed by the circumstance of life. Those with spare time on their hands should keep developing their talents and acquiring knowledge in order to be able to act wiser later.

\section{Wisdom as Complete Knowledge}

Surprisingly, the most promising and the closest to pragmatism seems to be Plato's idea or form that represents wisdom as complete knowledge; in pragmatism, knowledge is applied, then assessed by the results of the subsequent corresponding actions. Abstractions are likely unattainable; they are known only from their imperfect reflections in its real referents. It is impossible to articulate sufficient reasons for wise actions. All of the necessary factors are never known in advance, however, so viewed wisdom is still gradable by the ordered levels of its completeness; it is 
a developing concept, not an absolute, as some reviewers interpreted it. Completeness of knowledge precisely defines the upper limit of the notion of wisdom, where each component is a granule of verified, replicable (in tests with different concepts or models of action) knowledge, while each doubt or lack of clarity is a granule in the subset that defines incompleteness - a complementary subset. If the universe is infinite, wisdom must be infinite, while if finite, wisdom must be a closed finite set of granules of knowledge.

Recently, scholars have become aware that, in the digital era, knowledge stored in knowledge bases consists of demonstrable, observable, verifiable, and replicable (in tests) granules or chunks. Kurzweil's (2012) theory of mind is that the neocortex stores all information as patterns, arranged in a hierarchy such that low-level recognizers feed bits and pieces to higher levels, which then determine what is being perceived. In addition, when a pattern is developing, the higher levels can feed down to the lower ones to anticipate finding a particular detail. This supports the notion of granules or chunks.

Contemporary actionably reliable knowledge consists of replicable-in-tests granules of information, data about things and events, propositions of the type "knows what," "knows that," "knows why," "knows how to reason," "knows how to act" (skills), concepts, models, patents, licenses, topologies, and sequences of state transitions of computers or robots (programs). These granules of knowledge may be factors in reasoning and actions. Thus, wisdom, viewed pragmatically as complete knowledge of verifiable granules that are assessed by the praxiological triad of criteria - ethics (here rational), effectiveness, and efficiency - makes such defined wisdom susceptible to computerized knowledge management and makes it manageable.

Not all factors contribute to a defined purpose; some may be counterproductive. In discussions about information, data, knowledge, and particularly wisdom, scholars seem to be under a spell (it acts like a common tenet, doctrine, or even paradigm) that they are resources, hence assets on which one may always rely in need, while, in practice, they may be neutral, positive, or even negative when viewed as to how and what they contribute to a purpose. Such bias distorts reality and, subsequently, the veracity of statements made about information. The same happened to information and knowledge. Hundreds of treatises have been penned to elaborate the notions.

The operational pragmatic approach defines information by its distinguishing properties (characteristics) as a pattern of physical states of energy/matter of their carrier that mainly, by their form, may symbolically represent something else; they may be stored or communicated (Gackowski, 2012a). Even Aristotle had a more sound and less distorted view of information than many of our contemporaries. He said that matter and form are one, that they cannot exist separately one without the other. A brick is more informed (in form or well formed) than the clay it is made of, as is the house made of bricks. In operations, any symbolic pattern with regard to its form (only the form) may become a factor in form, such as information, data, knowledge, concept, or even wisdom, if defined as evolving complete knowledge. Other factors, such as tools, machinery, or materials, are factors in substance. The former may be communicated or transported; those in substance must be transported to a different location (a necessity). A physical pragmatic approach to notions demystifies them from human-added dust and fog that confuse minds.

Now, the reader may need a warning. The presented model of thinking dissociates itself entirely from the widely accepted view of information as subjective (peculiar to individuals) interpretation of observations; it limits itself only to the its physical aspects as a natural phenomenon of factors in form and its material consequences in action according to a defined concept that ultimately leads to a mental or formal model of operations. Within this context, data (a human concept) are only a subset of available factual information, also called givens. Within such a context, we begin with some information, first to arrive at some factual and available (given) information, a subset called data. The impact of information or data on the results must be tested in action; it tests a 
concept or model of operations. This leads to a revised IDCKW model: Information-(anything in form)-Data (available or given factual information)-Concept (of action)-Knowledge (as defined above)-Wisdom (as the idea, form, or abstraction of complete knowledge).

\section{Knowledge Management and Control of Existence}

Managing anything becomes a challenge when the amount of the subject reaches a critical level. Even trash and waste management can overwhelm the finances of large municipalities; however, there is relative clarity about what trash and waste are, whereas the understanding of the components of DIKW remains relatively controversial. We still debate what information and data (whether primary or secondary) are, what concepts are, and what knowledge is, with some scholars even declaring them indefinable and with wisdom left to generalities or, better, silence. The quality of these components is an even bigger problem. Verifiable, replicable in tests, granules of knowledge makes them actionably reliable. This is what separates professional knowledge management from knowledge trash management - a distinction rarely made but discussed by Gackowski (2012).

Humans explore or conduct research concerning various concepts to enhance their understanding of the existence of these concepts because such knowledge offers more control over their existence, as advances in science and technology demonstrate. It tempts one to speculate that complete knowledge may ultimately mean complete control over our existence. This way of thinking about wisdom differs from wisdom portrayed as the knowledge and art of passive adjustment to current reality in contrast to the active, creative conquest of matter by the human mind or intellect. This leads to cultural differences, not only between nations, but also between different social groups within a nation or at different historical periods of development, such as individualism and collectivism, with observable results. As approaching equality of potentials or states of entropy would lead to extinction of life and thermal death of the universe, so fully exploited (not subdued) differences among individuals with regard to their talents and gifts demonstrate how humans may be gaining control over their existence. At least in the Judeo-Christian tradition, it is expressed as "let them have dominion over all the earth," which includes a strong work ethic. After the Dark Ages, this attitude led to unprecedented and unparalleled advances in science, technology, and economy, which transformed societies all over the world.

\section{System of Reference for Pragmatic Wisdom}

Thus, the main point of reference (measurable purpose), the frame of reference (the stakeholders and other affected entities, including different concepts of actions), and the unit of measure of the purpose may also constitute a clear system of reference for the notion of wisdom as Einstein advises. It is an untrodden path of thinking about wisdom without the lofty words, academic musings, and subsequent misconceptions. Any new model, however, should be tested to find out whether it is valid.

When randomly selected people are asked to answer, if possible without reflection, that, if someone learned about new facts, acquired new methods of thinking, or proceeding (skills), did he wise up or vice versa when he forgot some of the useful ones, responders did not hesitate in their perceptions about when one is wiser or less wise. It was only a thought experiment but easy, effective, and inexpensive. To the horror of some, it can be called the test of "the least among us understood what the great ones could not" (e.g., that the emperor has no clothes). Academicians - the great ones, at least many among them - declared wisdom beyond the possibility of being defined. Common people (such as those who were randomly asked) do not complicate things unnecessarily; even theologians quoted by Stefanowicz surprisingly did not raise the issue despite the fact that it can found in the Bible. 


\section{Limitations of Knowledge}

Does a zero level of operational knowledge exist? It seems not, because even a stem cell, a computer with empty memory, or a newborn baby possesses built-in instructions for the first stage of existence. Life could not continue otherwise. There is an inherent bias in academic thinking. Contrary to many scholarly claims, information and knowledge may literally be poisonous, as damaging as physical booby traps. They may be counterproductive with regard to the purpose of our actions, such as bloodletting prescribed to strengthen sick patients while gradually killing them. Some will arrogantly say that this was the case only in the eighteenth and nineteenth centuries. In the 1950s, however, medicine treated chest pains attributed to the heart by cutting the chest open with or without doing anything. For about one year, it yielded only a positive placebo effect but at an enormous unnecessary cost for health care (Ariely, 2008). In the twenty-first century, many economists still, without hesitation advise - to the delight of politicians seeking re-electioncuring excess debt by taking on more debt. All of this is supported by those on the receiving end: individuals, corporations, and their friends. Every house husband knows it will make things worse, except for some of the learned ones. This is a contemporary economic bloodletting, but, there is a commendable exception: It might help when the money is borrowed for highly productive, effective, and efficient projects that, by generating high returns, it may reduce the debt. Governments are unable to do it; usually they finance failed but favorite programs. The historical record verifies the failure of centrally planned economies.

Scholars overemphasize positive effects while ignoring negative aspects. Advances in science focus on truth or replicability of results, not acceptance of views. Science is beyond good and evil; as with everything, it can be misused and abused. Thus, one cannot ignore that knowledge may also be counterproductive if only accepted but not verified with regard to anyone's purpose (the main point of reference) unless one untenably assumes that knowledge is invariably useful.

Simon (1956) noted that humans are limited to bounded rationality because we are unable to recognize all contributing factors. Kotarbinski (1961, pp. 189-201), looking at the same problem from a different perspective, provided a proof that perfect rationality is impossible. Tsing (1993, pp. 243-255) recognized it as an achievement not inferior to Hume's principle that causality cannot be proven. He refers to it as the Kotarbinski-Simon problem of unattainability of perfect rationality. It is surprising that even Polish scholars ignore how wisdom is related to praxiology (with much articulated in Poland), which is the theory of human conduct and behavior (Gasparski, 1988), particularly its fundamental ordered triad of ethics, effectiveness (measures the extent of attaining the purpose), and efficiency (ratio of effect and inputs). Thus, we arrive at a partially ordered set of granules of knowledge.

Many consider that unattainability of perfect rationality is not the only hurdle in attaining wisdom, as defined above (complete knowledge with subsequent corresponding actions within the confines of rational ethics). Many scholars claim that neither individuals nor the entirety of humanity will ever be able to attain complete wisdom about the universe because humanity constitutes only a submicroscopic part of it. It sounds logical; however, not many scholars who publish are aware that more than two millennia after Aristotle, Frege, and B. Russell (he rediscovered Frege's monumental achievement), logic, including mathematics as abstract constructs, do not make statements about reality, only about propositions. Following logic only, one may end up with something similar to the infamous statement made by Lord Kelvin (Kelvin, 1902) (Thompson his family name), literally a theoretical and practical genius who responded in his interview, "Then we cannot navigate the air at all in a commercial way?" "No; I think it cannot be done. No balloon and no aeroplane will ever be practically successful." One can see that even a genius was unable to infer from the daily experienced graciously or swiftly flying birds that it is physically possible. It also represents underestimation of exponential growth of knowledge and, hence, technology that is common to almost all of us. 
If a mustard seed, the largest of all garden plants, can hold all the information (a template) of the knowledge about HOW to grow (not whether it will grow due to external constraints in a specific situation that is subject to knowledge about agriculture), then, simply, we have not yet known how to store the entire or even partial knowledge about the universe in such a small entity. Today, however, we know that information may be stored and retrieved from strands of DNA, and this is how the mustard seed does it. According to those who claim receiving some insight, these principles are simple and beautiful. Certainly, it was not easy for Thomas Aquinas to declare the fruits of his life-long labor, his opus vitae — one of the most sophisticated philosophical systems (whether one agrees with it or not), as "straw" that is not worth any more labor. Afterward, Aquinas refused to dictate any of his thoughts. Of course, such insights, even as claimed by not so few others, are not demonstrable and replicable; hence, it cannot be part of rigorous science. Thus, let's leave unanswered the question of whether it is possible to attain complete knowledge, hence wisdom.

\section{Indirect Approach to Knowledge}

Once we cannot go beyond or even reach the barrier of perfect rationality, we cannot directly observe and measure the results of wise decisions and subsequent actions. The barrier as proven appears to be insurmountable. Nevertheless, logic knows indirect proofs. Humans easily notice results of imprudent decisions and actions, particularly when committed by others. The Law of Unintended Consequences applies; we learn about factors not taken into account only after a practical implementation of any project, and this may subsequently change the concept of action. This is the process of learning by trial and error. Thus, biological entities (mutations), including humans, adapt to existing and changing situations when they do not insist on repeating the same action while expecting different results.

On one hand, within the sector of information technology alone, an entire industry of products and services mushroomed to address the issue of unwise actions. On the other hand, with relative ease, one can assess the fast-growing cost of the law enforcement, prison, and parole systems in general. It likely provides only a fractional indication of the financial burden placed on society by the breach of ethics and morality and on legality as the minimum of morality. Contrary to the benefits of wise decisions that no one is capable of assessing (cost/benefit analyses of projects imperfectly tries to do it), the cost of unwise choices is assessable. Thus, by focusing attention on the most costly unwise choices and actions in a society, one may re-enter the realm of the measurable, hence likely manageable. With regard to wisdom, the essence of the offered position is to focus on addressing what causes or significantly contributes to unwise choices and behavior that burdens all of us.

\section{Principles of Wise Actions}

According to the current state of knowledge, wise actions rely on

- employing the tried and verified methods and rules of proceeding, limited by bounded rationality within different concepts or models of actions

- preventing irrational decisions and behaviors (e.g., unauthorized security transactions, unauthorized access to nuclear warheads, leaking of secrets, etc.)

- engaging in ethical arbitrage, if possible, or automatic arbitrage in making a decision without crippling delays. (It may be impossible to make an unambiguous choice between near-simultaneous events under a deadline [Denning, 2007] because systems may hang up.) 
It seems that projects and endeavors reaching beyond the known and beyond rationality can be done only by trial and error, which is expensive. These expenses may be reduced by using simulation, models, or prototypes and starting with pilot implementations on a limited scale - another example of prudence. Similarly, the use of agile methods reduces the risks involved in developing information systems, as one reviewer pointed it out. The above is a brief overview of the pragmatic model of wisdom in action. Now, let us confront it with opinions about wisdom that have been expressed by selected scholars.

\section{Pragmatic versus Academic Wisdom}

Selected quotes with comments:

1. The saying, "The only true wisdom is in knowing you know nothing," is attributed to Socrates.

Author's comment: It was an overstatement. We know that Socrates developed a method of acquiring knowledge through dialog. Thus, even he, like other authors, seem to agree that one needs some knowledge to be wise.

2. What knowledge one possesses, it ought to be used (act in accordance with the knowledge), Fricke, 2009, p. 141).

Author's comment: If not used, it becomes squandered knowledge (talents), by the way, exceptionally mercilessly punished many times in the Bible: This provides a hint for those with spare time on their hands to utilize it for developing their talents. Wisdom assessed without examining subsequent action is pragmatically meaningless.

3. According to Floridi (2004), wisdom applies to the selection of purpose, the "appropriate ends of life."

Author's comment: Everyone sees them differently; thus, generalization is impossible. Floridi's statement goes beyond replicable knowledge and remains open for all possible interpretations, as, alas, preferred by many philosophers teaching ethics.

4. Knowledge should be used prudently within the confines of the golden rule of moderation by refraining from extremes by considering further consequences (e.g., how to recognize and avoid dangers [Nozick, 1989].)

Author's comment: It is known that, sometimes, even well-intentioned actions may cause more harm than good (e.g., helping an elderly person to get up after a fall without checking for possible injuries, according to procedures taught to nurses: "first, do no harm"). Here we encounter real difficulties because, with incomplete knowledge limited by bounded rationality, we are unable to foresee everything. It requires many trials to detect deficiencies in our prudence. This is how time-tested rules are developing.

5. Faucher et al. (2008) summarize by claiming that "Wisdom is understood as a meaningful, procedural, and justified abstraction of existence based on experience. It has a purpose, relates to procedures, but it is also based on a coherent judgment of existence justified through experience. Wisdom therefore permits sound action and use of experience. Wisdom requires a higher level of understanding than data, information, and knowledge" (p. 12).

Author's comment: The authors amassed nice-sounding adjectives without a defined system of reference. "Meaningful" was used within linguistic or natural semantics? Similarly, "justified," "sound," but in what respect? The authors acknowledge that there is a role of purpose in wisdom. One may understand, coherently judge, and make decisions, 
but without action, one cannot be sure whether it was even relevant to the situation. The above adjectives sound nice, when one charitably interprets existence according to dictionaries, as "reality as presented in experience"(Merriam-Webster). However, Faucher et al. articulate it in a different way: "Existence describes the whole environment that humans can grasp and create data about. It is a state of being that constitutes the lower end of the knowledge system" ( $p .8)$. More author's comments: (a) Existence does not describe anything; it IS; (b) Can a state of being be procedural? (c) How does a state of being become knowledge? (d) How does one measure levels of understanding? (e) To the surprise of the quoted authors, "created" data should be regarded as fraudulent. One cannot create facts; one may gather or collect factual data.

6. Giambattista Vico, an Italian philosopher, wrote: "wisdom," which is "nothing but the science of making such use of things as their nature dictates" (Element CXIV, §326, p. 94, as quoted by Costelloe, 2012).

Author's comment: What is the nature of things? Even a human is not sure about his own nature. It is a passive approach to existence, which runs counter to the essence of pragmatism that, contrary to passivists, strives on improving our existence. Having a gun, should we shoot indiscriminately because that is what its nature dictates?

7. Liu (2006) presents wisdom in the light of the teachings by major schools of Chinese philosophy. For instance, (a) Adjustment to and divination of the rhythm of the Universe is a prerequisite for wisdom in ancient folk religion (pp. 3-4) and is continued by Daoism (pp. 22-23); (b) Cessation of all discriminating (analytical knowledge) consciousness leads to attainment of so-called "noble wisdom," even the enlightenment in itself, according to Buddha in the Lankavatara Sutra (p. 310). Thus, in this interpretation, wisdom is a transformed consciousness (p. 230). (c) One should not adhere to anything, including even "nothingness," and assign equal value to all things, according to Buddha in Diamond Sutra. Thus, enlightened understanding, or awakened consciousness, is called "wisdom," which is not easily enslaved by ideology, fashion, and trends (p. 310).

Author's comment: From the Western perspective, on the one hand, they all are "thisworldly" realist philosophies that do not deal with "other world philosophies. Yes, sometimes they are supported by Heaven but not necessarily sanctioned because "the ruler is Heaven by Mozi and Heifeizi" (Liu, 2006, p. 24). All of them focus on adjusting to the reality one faces, a kind of passivity. The rejection of discrimination, meant as analytical knowledge, hinders contestation and advancement. There is nothing wrong with the adjustment to the rhythm of the Universe. It is wise, but only as a starting point, not the end.

Rowley (2007), in her vast review of literature about DIKW, lamented the limited discussion of the concept of wisdom. She provided three opinions. Here are the first two. The third one will serve as an introduction to Section 4 about rational ethics in pragmatic wisdom.

- Jessup and Valacich (2003) see wisdom as accumulated knowledge, which allows us to understand how to apply concepts from one domain to new situations and problems. Author's comment: They agree that wisdom consists of knowledge but limit wisdom only to the ability to transfer what we know from one domain to another. It is an interesting view that leaves its purpose to the reader's imagination.

- Awad and Ghaziri (2004) suggest that "Wisdom is the highest level of abstraction with vision, foresight, and the ability to see beyond the horizon" (p. 40). Author's comment: Highest level of abstraction of what? However, vision, foresight, and the ability to "see beyond the horizon" (whatever the last means) within a defined system 
of references may make perfect sense; otherwise it is useless. On the same page, these authors offered a better quote: "within the context of goals and values of life," but these as peculiar to individuals are subjective.

It appears that the pragmatic model of wisdom that is presented in Section 2 stands fairly solidly when confronted with the views presented by the quoted authors. It is for the reader to decide whether it provides a sense of direction, a sense of purpose, and the necessary context and, thus, may serve as a possible framework for further research concerning this subject, and, finally, whether it is research at all and of what value it is, as one reviewer doubts. Wisdom intrinsically entails ethics (here, rational ethics).

\section{Rational Ethics for Pragmatic Wisdom}

Within the triad of praxiological criteria (ethics, effectiveness, and efficiency), the last two can be defined in a rational manner relatively easily (see Section 2 ). Ethics eludes many efforts. It connects to established laws (the minimum of morality) and different interpretations in different cultures, religious precepts, and beliefs. For these reasons, it presents a formidable challenge. One cannot expect from ethics more than guidance by those who seek guidance and choose to follow. As all living entities, humans are opportunity-seeking creatures. For individuals free to choose, ethical guidance can be neither universal nor mandated. Behavior enforced by law or social pressure cannot be assumed to be ethical, but it may overlap ethical behavior. Let's review some contemporary views concerning ethics.

\section{Contemporary Views about Ethics for Wisdom}

Jashapara, as reviewed by Rowley (2007) directly addressed ethics and wrote, "Wisdom is the ability to act critically or practically in any given situation; it is based on ethical judgment related to an individual's belief system" (Rowley, pp. 17-18). Thus it is impractical for pragmatic wisdom because it may be the subject of multiple interpretations. Other philosophers attempted rational articulation. Confucius reduced it to "reciprocity": "Zi Gong asked, saying, "Is there one word that may serve as a rule of practice for all one's life?' The Master said, 'Is not reciprocity such a word?"” (“Confucius," Wikipedia, 2013). Immanuel Kant ("Immanuel Kant," Britannica) articulated the categorical moral imperative: "Act only according to that maxim by which you can at the same time will that it should become a universal law"; it seems to leave no wiggle room, no fuzziness. It is still the best-known attempt of an unambiguous, rational, and brief articulation of ethics. It is categorical; it refers to a single main point of reference to "you" as a rationally thinking individual acting in your own interest. For the individuals who may act irrationally, the pragmatic model of wisdom in Section 2, which also applies to informing systems, contains the clause, "prevention of irrational decisions and behavior." However, not many see it this way.

What do scholars who teach ethics offer? They prefer to remain silent, not quoted, or wrote,

- "Rational belief that a moral theory that ignores human emotional life is not really about human beings, and therefore not really about morality." Author's comment: Human emotions cannot be ignored in actions, but, when irrational, they should be prevented.

- "Any situation that is at all ambiguous, or about which we have incomplete informationwhich is to say, every real situation in the world, where morality might make a difference-would seem too complex for this reductive notion of moral decision-making. In philosophical ethics, we do not imagine that we have final wisdom and the correct answer about ethical issues or theory. We teach multiple approaches to ethics, even antithetical to one another, for that very reason. Knowledge of ethics is the capacity to consider situations from multiple perspectives, and that, not a formula, is ethical wisdom. The fundamental guidance philosophy can offer is the cultivation of wisdom. It appears 
you are looking for ethics to provide a precise, positive, unambiguous answer to some ethical dilemma. They are ethical dilemmas precisely because, due to the ambiguity of situations, and the limitations on human knowledge and judgment, no human being has such an answer - at least, not one that is not likely to be dogmatically drawn from some orthodoxy. The study of ethics can provide that cultivation of wisdom. The first step in developing it, as has been recognized in the history of Western philosophy since Socrates, is to admit that we do not have, in hand, the right answer... As long as you return to this dogmatic position (pragmatic granular approach to wisdom - explanatory comment added), you will not actually enter into ethical reflection." Author's comment: This removes morality from decision making in complex situations; it is a strong and interesting statement but enables one to eliminate ethics from decisions; it reflects the view shared by too many that morality is relative, that no one is qualified to judge another; it is nihilism.

Socially, any real act is also a moral statement that provides a pragmatic answer about its ethical consequences. Philosophers teaching ethics want to avoid providing ethical guidance, even at a price, up to admitting that, since Socrates, they have not made any real progress. Thus, as with data, information, knowledge, and wisdom in general (see Stefanowicz, 2012), this, again, for a pragmatist, is a convoluted declaration of an unconditional intellectual surrender.

However, nearly invariably, those who teach ethics hold Peter Singer in high esteem. Britannica's selection of his article about ethics confirms that his views represent the state of art at least among professionals in this domain. They write more: "Frankly, it is rather shocking that your source for this interpretation of philosophical ethics is an encyclopedia article, rather than the texts themselves, or what would be genuinely scholarly and reputable sources-the long tradition of Kant scholarship, in this case. This would never be acceptable in an introductory philosophy course for undergraduate freshmen, let alone as a form of scholarly practice." Author's comment: Alas, this is an infeasible proposition for average individuals who must act to live.

While waiting for assistance from those who professionally deal with ethics, this author made thought experiments that may not be considered representative. However, extreme war conditions (WWII) offered many ethical challenges. To the surprise of the ever-reflecting scholars, Kant's rational categorical imperative not once failed in providing clear guidance to one who lived through that war in Poland. It does not mean a guidance that is easy to follow; it required heroism, which cannot be mandated. Thus, the categorical imperative found itself under assault.

\section{How Singer Errs Criticizing the Categorical Imperative}

Only a short exchange of opinions with anyone around reveals a diversity and disparity of interpretations. In ethics, most individuals find it difficult, if not impossible, to separate rationality from morals, values, and judgments, while the "categorical imperative, in the ethics of the 18thcentury German philosopher Immanuel Kant, the founder of critical philosophy, is a moral law that is unconditional or absolute for all agents, the validity or claim of which does not depend on any ulterior motive or end" ("categorical imperative," Britannica; emphasis added); commands of morality must apply to all rational beings regardless of their wants and feelings. This poses an insuperable problem for many because it represents a formal logical statement and expresses the condition of the rationality of conduct.

Peter Singer ("ethics," Britannica) discusses and criticizes the categorical imperative in the following manner: "Kant gave closer attention to the problem of how his supreme formal principle of morality can provide guidance in concrete situations. One of his examples is as follows. Suppose that a person plans to get some money by promising to pay it back, though he has no intention of keeping his promise. The maxim of such an action might be: "Make false promises when it suits you to do so." Could such a maxim be a universal law? Of course not. The maxim is self- 
defeating, because if promises were so easily broken, no one would rely on them, and the practice of making promises [also lending money] would cease. For this reason, the moral law would not allow one to carry out such a plan" (emphasis added). He continues.

"Not all situations are so easily decided, however. Another of Kant's examples deals with aiding those in distress. Suppose a person sees someone in distress, which he could easily help, but refuses to do so. Could such person's will serve as universal law or a maxim that one should refuse assistance to those in distress? Unlike the case of promising, there is no strict inconsistency in this maxim's being a universal law. Kant, however, says that one cannot will it to be such, because one may someday be in distress oneself, and in that case one would want assistance from others. This type of example is less convincing than the previous one. If the person in question values self-sufficiency so highly that he would rather remain in distress than escape from it through the intervention of another, then Kant's principle would not require him to assist those in distress." Author's comment: One can see how Singer disregards Kant's rationality and injects "values" with irrational adherence to them. Are there documented cases that a person drowning refused to accept help because he cherished self-reliance more than this life? This statement distorts rationality. The majority, if not all, expect to be helped. He entered into academic musings.) "In effect, Kant's supreme principle of practical reason can tell one what to do only in those special cases in which willing the maxim of one's action to be a universal law yields a contradiction. Outside this limited range, the moral law that was to apply to all rational beings regardless of their wants and desires cannot provide guidance except by appealing to wants and desires" (emphasis added). (Author's comment: Singer interjects an irrational desire to remain self-sufficient at any cost in order to question the universal validity of the purely rational first imperative.)

It gets even worse; Singer says: "Kant does offer alternative formulations of the categorical imperative, one of which appears to provide more substantial (emphasis added) guidance than the formulation considered thus far: 'So act as to treat humanity, whether in your own person or in another, always as an end, and never as only a means"" ("Immanuel Kant," Britannica). Now:

1. He had to resort to tortuous arguments for a case about slaves and slavery, while failing to notice that, in the first, imperative slavery would be impossible; who wants to become a slave? This simple solution eludes Singer. He prefers the second imperative that leaves room for convenient interpretations. Particularly black slaves were simply dehumanized, even by likely not the worst among humans, such as the slave trader, Newman, whose beautiful "Amazing Grace," written after he realized the error of his ways, but not after abandoning the slave trade, is sung in most English-speaking churches. With the rational categorical imperative, even animals would be treated better. Who wants be treated as animals? This paper posits the superiority of the rational categorical imperative over other attempts.

2. Singer reached the bottom by ignoring the present state of philosophy of science. The unambiguous ' $y o u$ ' in the first imperative, Kant replaced with "humanity, whether in your own person or in another" (today about SEVEN BILLION). Such humanity entails war criminals, mass murderers, child molesters, stoned drug addicts, decently working people, highly skilled people, geniuses, heroes, and saints as well - a heterogeneous fuzzy set, a single point of reference with a nebulous cloud of points of reference; which one did Kant mean? It is as if, in astronomy, someone selected an entire galaxy as a reliable point of reference. No reliable observations and inferences can be made without a welldefined point of reference; otherwise, in ethics, anything may go by individual preferences; it is surprising that other professional philosophers, including those employed by Britannica, have not questioned it. 
Certainly, Kant (nevertheless the co-author of the Kant [1755]-Laplace [1796] nebular hypothesis in astrophysics) has not noticed that, with the second version of the categorical imperative, he regressed from the heights of precision to subjective comparisons with a variety of humans; he fell into the well-known trap of thinking that humanity consists only of valuable members. One of the forgotten Chinese sources claimed that, according to some of their definitions, a human is an animal plus something more; hence, no one knows whether it is for better or worse. Thus, entire humanity, as nice as it sounds for many, is pragmatically useless as an unambiguous point of reference, particularly in international relations. (A heterogeneous set of members cannot serve as a reliable point of reference; it is doomed from the beginning by faulty design.) There are widespread ideologies, religions, and views that deny humanity and human rights to others, even entire races, nations, and other religions by which bombing of a church of another denomination is not only ethical but also commendable. The rational categorical imperative does not allow for such disparities, hence is much stronger. By this imperative, if followed and enforced, anyone proposing excluding others from humanity would exclude him or herself with no recourse. Even polluting innate air, water, and soil could not slip through. Would anyone wish to be polluted?

Thus, Singer errs by looking for imperfections in the articulation of Kant's first (rational) categorical moral imperative, while attaching more substance to the second. By the contemporary philosophy of science, the second imperative is an intellectual construct that is defective by design; it refers to a nebula of points of reference. This paper posits that Kant's rational categorical imperative that refers to the single "you" remains perfectly valid. Now, let us move toward the rational position.

\section{The Rational Position in Ethics}

This paper stays away from morals because science is beyond good and evil. Morality deals with intentions with no hope of finding consensus. The pragmatic approach is limited to results with regard to a stated purpose. Before triggering action, one should plan it within the praxiological triad of criteria, among which ethics is the first one. How does the rational version of Kant's categorical imperative stand within the system of references proposed for the pragmatic view of wisdom in Section 2? It pertains to any act, it provides a complete existential context, and it does not require a system of values for moral judgment, but rationality of the agent, where

- the agent ("you") is the main point of reference.

- everyone and everything affected by action, including a selected concept of its conduct, and agents constitute a complete frame of reference.

- the yardstick is the same for all and everything - a unit of result that the action yields applies equally to everything affected with no wiggle room.

It will not be used by agents who do not care about ethics. Alas, the antithetical approach leads to "moral relativism." For those who wish to see guidance, there are on the market books dedicated, for instance, to "corporate ethics" in the Harvard Business Review on Corporate Ethics (2003) or Corporate Ethics and Corporate Governance (Zimmerli et al., 2007).

Rational ethics does not refer to even the simpler precept of "love your neighbour as yourself" (by five centuries preceded by Mohoism in China [Liu, pp. 22-23]) because commandments given from Heaven (also in China - the Emperor) are not acceptable to adherents of other faiths. At least by one major religion, faith is granted by grace only; hence, by definition, not for all. This excludes religiously grounded ethics as incapable of serving all. We should not ignore them but consider them separately from the rational ones.

Before closing this section, it may be instructive to add comments on Jashapara's (2005, pp. 1718) view of ethics quoted before: It is subjective because it is based on individual beliefs. Science 
needs unbiased criteria of how to judge actions by results with regard to a stated measurable purpose, without imposed "values" that are frequently indefinable by proponents such as "good," "evil," "just," or "fair." Values may appear beautiful and good and produce disastrous results. Compare the USA and Russia, two countries about equally rich in natural resources. Of course, the USA before 1913, without much government intervention except for graft, where everybody acted mainly in his own interest, grew to incomparable power. In 1917, Russia embarked upon building communism "for the common good" that yielded hunger, poverty, and terror until the system broke down. The commonly denigrated criterion of personal gain turned out better results, while the glorified common good failed, not for the first time; it failed the first Pilgrims in Massachusetts who, nearly starved to death, mandated that everyone must work for "the common good." Effectiveness and efficiency equally serve good and bad purposes.

Scholars forgot that ethics, depending on the situation, may easily accommodate, as once did cannibalism, live sacrifices, purity of race, the supreme interest of the abstract workers, and now even wiping out another race or country from the surface of the Earth as moral imperatives. Academia suffers a seemingly incurable disease of well-intended bias toward "good" in spoken and written word, regardless of consequences. Lofty "values," combined with deeply held convictions (Paris educated Pol Pot, seminarian Stalin), when bestowed with real power, sacrificed tens of millions of people for their vision of a promised better future to maintain power.

These words are not to critique the intentions of the quoted author, but, rather, highlight the evident lack of vision, foresight, and ability to see beyond academia. It is time for conclusions.

\section{Conclusions and Limitations}

This paper presents wisdom within the IDCKW model of thinking that begins with

- Information (anything in form, distinguishing properties [characteristics] as a pattern of physical states of energy/matter of their carrier that, by their form, only may symbolically point to something else; it may be stored or communicated-a natural phenomenon that is independent of its interpretations by living organisms)

- Data (available or given factual information - a human-devised concept)

- Concept (a mental/formal model of actions that plays the central role in the pragmatic model of thinking about the remaining components of the model and makes possible their assessment and verification)

- Knowledge (verifiable and replicable-in-tests of actions, conducted within defined concepts, granules of information, factual data about things and events, propositions of the type, "knows what," "knows that," "knows why," "knows how to reason," "knows how to act" [skills], concepts, models, patents, licenses, topologies, sequences of state transitions of computers or robots - programs)

- Wisdom (pragmatically defined as an abstract idea of complete knowledge)

Pragmatic wisdom is a gradually accumulating complete knowledge that consists of countable, verifiable, and replicable-in-tests granules within a concept of actions. Thus, defined wisdom is susceptible to computerized knowledge management that makes it manageable, which is a goal of this paper. Actions are assessed from the perspective of a measurable purpose as interpreted by interested stakeholders within rational ethics. As an abstract idea, it may never be fully attained as other abstract ideas; however, it offers a framework for measurable progress. (Most individuals are surprised when they hear that a perfectly straight line does not exist in reality.)

Only some seek ethical guidance at all, but it offers a reliable way of reasoning before acting. Pragmatically, knowledge is limited by the bounded rationality of human actions. Anything that 
exceeds bounded rationality can be cognized indirectly by trial and error; only with hindsight may one learn more from the unintended consequences. In contrast to many Asian philosophies that consider wisdom as a state of consciousness, the pragmatic approach requires a discriminating mind, resulting in analytical knowledge that is validated by results in action. This fosters advancement of science, technology, and economy. Wisdom, viewed within a defined system of references, refrains from imposing "values" but clarifies and adds direction to the adjectives so abundantly bestowed upon wisdom. At the same time, it lays bare the misconception of the "virtue" of deeply held beliefs and convictions; they may be held as long as facts do not prove them wrong; otherwise, the situation should be reconsidered and the conduct of operations should be changed again, testing the results. In practice, stubbornness takes the upper hand. For instance, in crises, the answer was to tighten central planning, or, when in debt, to take on more debt to revive the economy. Professionals in this domain prefer to replace rationality with nice-sounding adjectives: "appropriate," "justified," "sound," "higher level of understanding," "meaningful," "coherently judged," "procedural state," "state of being wise," "use things as their nature dictates" (when you have a gun, then shoot), "state of consciousness," "act critically and practically" (but how?). All of the above makes wisdom a mystery beyond the grasp of common sense and does not contribute to the practical application of wisdom by those who must act to live and have not time to study the history of philosophy.

With humans, as opportunistic as they are, there are factors that hinder rationality. They differ for individuals, for organizations, and for associations of individuals. Kant's first categorical moral imperative seems to provide particularly effective guidance for individuals who seek it, but frequently it collides with entrenched group interests that an individual may belong to or when it may require courageous and even heroic actions, while heroes and saints are a miniscule minority among us.

Organizations and associations are established for some purpose. Each of them claims the need for special privileges that, once obtained, whether justified in any way or not, will be ferociously defended. Even when the original purpose has been forgotten, a new fake one will be articulated and promoted. They address particular interests with the approval of the rest and are perpetuated ad infinitum, but cannot become a universal right and easily degenerate.

Alas, even medical associations are not free from violating ethics where ethics was considered a paramount requirement. For instance, the popular vitamin niacin can be distributed in the USA without prescription, in Poland only below certain strength amount, while in Australia a physician's prescription was always required. Some say this is to compensate for regulation of fees charged per visit, thus subjecting patients to more frequent medical appointments (unintended consequence to compensate for other regulation). It is difficult to imagine that different health conditions could justify such different approaches in this simple case; regulations are rarely to never passed without input, pressure, and lobbying. Other such examples from other professions are easy to find.

However, for the sake of academic deliberation, further research into knowledge management is important. One must take into account subjective interpretations of observations; hence, research should not limited only to the pragmatically defined, actionably reliable granules of knowledge. The ascending helix of cognition (Gackowski, 2012b) begins with loose interpretations of observations. Thus, there is a need for a broader interpretation of knowledge than that which is pragmatically defined in this paper. We need to make at least the following distinctions: articulated interpretations of observations (the not-yet articulated cannot be subject to any), articulated interpretations still subject to scholarly deliberations such as Singer's critique of Kant's categorical imperative, the articulated but ultimately rejected interpretations such as the ether in physics or the sun revolving around the earth, and, finally, the verifiable and replicable (in testing) granules of actionably reliable knowledge. Certainly, further research is needed about how to manage ar- 
ticulated interpretations of observations and avoid confusion with the reliable ones; for instance, in ethics the "reciprocity" by Confucius or the rational categorical imperative by Kant that leaves no wiggle room for misinterpretation.

This paper offers a fill-in for the gap about wisdom that is deplored by many authors) within the IDCKW model that focuses on the rationality of pragmatic outcomes, but does not ignore the central role of 'concepts' in this model. It is presented for challenge, critique, and discussion. Readers are encouraged to take a position that is supported by arguments, to share their views at the email address of the author, and to help articulate it better, this time for the common good. Readers will decide whether it adds anything to their knowledge or, as one reviewer stated, "it is not research at all and of no research value." This terse assessment short on specifics makes impossible to address defects. Academic critique is in a sorry state. Most reviewers prefer to focus on the fringes and format, while rarely to never head-on challenging the essential thesis of the paper, unless the review is only about readability. They act like lightweight toreadors evading the heavy bull, where it is fully justified by the sheer physical necessity, while not desirable in academic critique.

\section{References}

AHTD. (1997). In American heritage talking dictionary. Chicago, IL: The Learning Co.

Ariely, D. (2008). Predictably irrational: The hidden forces that shape our decisions. New York, Harper Collins.

Awad, M. A., \& Ghaziri, H. M. (2004). Knowledge management. Upper Saddle River, NJ: Pearson Education.

Blackler, F. (1995). Knowledge, knowledge work and organizations. An overview and interpretation. Organizational Studies, 16, 1021-1046 doi.

Confucius. (2013). In Wikipedia. Retrieved from http://en.wikipedia.org/wiki/Confuciusism

Costelloe, T. (2012). Giambattista Vico. In Edward N. Zalta (Ed.), The Stanford encyclopedia of philosophy (Spring Ed.). Retrieved from http://plato.stanford.edu/archives/spr2012/entries/vico/

Denning, P. J. (2007). The choice uncertainty principle. Communications of the ACM, 50(11), 9-14.

Einstein, A. (1961). Relativity—The special and the general theory. New York: Crown Publishers.

Ethics. (2012). In Encyclopcedia Britannica. Encyclopcedia Britannica Online Academic Edition. Retrieved from http://www.britannica.com/EBchecked/topic/194023/ethics

Faucher, J. B., Everette, A. M., \& Lawson, R. (2008). Reconstituting knowledge management. Journal of Knowledge Management, 12(3), 3-16.

Floridi, L. (2008). The method of levels of abstraction. Minds and Machines, 18(3), 303-329.

Fricke, M. (2009). The knowledge pyramid: A critique of the DIKW hierarchy. Journal of Information Science, 35, 131-142.

Gackowski, Z. J. (2012a). Focus and perspectivism in viewing information, data, and informing: Fundamental distinctions. Informing Science: International Journal of an Emerging Transdiscipline, 15, $1-$ 35. Retrieved from http://www.inform.nu/Articles/Vol15/ISJv15p001-034Gackowski588.pdf

Gackowski, Z. J. (2012b). The helix of human cognition: Knowledge management according to DIKW, E2E, and the proposed view. Informing Science: International Journal of an Emerging Transdiscipline, 15, 93-119. Retrieved from http://www.inform.nu/Articles/Vol15/ISJv15p093119Gackowski614.pdf

Gackowski, Z. J. (2012c). Informing for operations: Framework, model, and the first principles. Santa Rosa, CA: Informing Science Press. 
Gasparski, W. (1988). Praxiology. In M. G. Singh (Ed.), System and control encyclopedia. Oxford, UK: Pergamon Press.

Harvard Business School Press \& Badaracco, J. L. (2003). Harvard business review on corporate ethics. Boston: Author.

Immanuel Kant. (2012). In Encyclopcedia Britannica. Encyclopcedia Britannica Online Academic Edition. Retrieved from http://www.britannica.com/EBchecked/topic/311398/Immanuel-Kant

Jashapara, A. (2006). Knowledge management: An integrated approach. Upper Saddle River, NJ: FT Prentice Hall.

Jessup, L., \& Valacich, J. (2008). Information systems today. Managing in the digital world. Upper Saddle River, NJ: Pearson/Prentice Hall.

Kelvin. (1902). Kelvin on science. Retrieved from http://zapatopi.net/kelvin/papers/interview_aeronautics_and_wireless.html

Kotarbinski, T. (1961). The property of a good plan. Methods, 13(51-52), 189-201.

Kurzweil, R. (2012). How to create a mind: The secret of human thought revealed. NY, NY: Viking Adult.

Liu, J. (2006). An introduction to Chinese philosophy: From ancient philosophy to Chinese Buddhism. Hoboken, NJ: Blackwell Publishing.

Margolis, J. D., \& Bettcher, K. E. (2005, December). Up to code: Does your company's conduct meet world-class standards? Harvard Business Review, 122-133.

Nietzsche, F. (2007). In Encyclopcedia Britannica. Retrieved from http://www.britannica.com/EBchecked/topic/414670/Friedrich-Nietzsche

Nietzsche, Genealogy, History. (2010). In Encyclopaedia Britannica. Retrieved from http://www.britannica.com.ezproxy.lib.csustan.edu:2048/EBchecked/topic/1308525/NietzscheGenealogy-History

Nozick, R. (1989). The examined life: Philosophical mediations. New York: Simon \& SchusterTouchstone.

Perspectivism. (2010). In Encyclopcedia Britannica. Retrieved from http://www.britannica.com.ezproxy.lib.csustan.edu:2048/EBchecked/topic/453084/perspectivism

Rowley, J. (2007). The wisdom hierarchy: Representations of the DIKW hierarchy. Journal of Information Science, 33, 163. Retrieved from http://jis.sagepub.com/content/33/2/163

Schopenhauer, A. (1974). On the fourfold root of the principle of sufficient reason. Chicago, IL: Open Court Publishing Co. (Original revised work published 1847).

Simon, H. A. (1956). Rational choice and the structure of the environment. Psychological Review, 63(2), $129-38$.

Stefanowicz, B. (2012, June). Pewne reflecsje w sprawie madrosci (Some reflections on wisdom). Biuletin Noukowego Towarzystwa Informatyki Ekonomicznej, Nr. 2.

Targowski, A. (1990). The architecture and planning of enterprise-wide information management systems. Hershey, PA: Idea Group Publishing.

Targowski, A. (2011). Cognitive informatics and wisdom development: Interdisciplinary approaches. Hershey, NY: Information Science Reference.

Targowski, A. (2012). Wisdom. Kalamazoo, MI: Civilization Press.

Tsing, Z. (1993). Philosophy of technology: Epistemological or praxiological? Some lessons from Chinese philosophy of technology. In T. Airaksinen \& W. Gasparski (Eds.), Praxiology: The international annual of practical philosophy and methodology, Vol. 2 (pp. 243-255). New Brunswick, NJ: Transaction Publishers. 
Zimmerli, W., Richter, K., \& Holzinger, M. (Eds.). (2007). Ethics and corporate governance. New York: Springer.

\section{Biography}

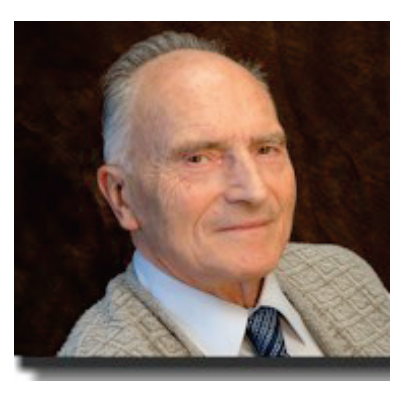

Zbigniew J Gackowski has experience in industry, public administration, and academia. His teaching and research bridge the Central European and US experience in Computer Information Systems (Warsaw Polytechnic, The University of Michigan [Fulbright Research Scholarship], Purdue University [Visiting Associate Professor], Baruch College [Visiting Professor], CSU, Stanislaus [Visiting and Tenured Professor], and the University of Melbourne [Visiting Professor]). His research has received much recognition. While in Poland, he published more than 120 items, among them 4 books and 6 papers in refereed journals and 12 papers presented across Europe, the United States, the Middle East, and South America. While in the USA, he taught at three USA universities and wrote 32 research papers that were published in the proceedings of ASIS, ACM, WDSI, Information Systems Educators Conference, The Informing Science Institute, and the International Conference on Information Quality at MIT (12 fast-tracked to peer-reviewed journals), 4 book chapters, and 1 scholarly book. He is a member of ACM, a charter member of the Association for Information Systems, and a founding member and honorary fellow of the Institute of Informing Science. 